\title{
Correction to: Cold Discomfort: A Model to Explain Repetitive Linear Enamel Hypoplasia Among Pan troglodytes and Pan paniscus
}

\section{Mark F. Skinner ${ }^{1} \mathbb{C}$}

Published online: 6 January 2022

(c) The Author(s) 2022

\section{Correction to: International Journal of Primatology https://doi.org/10.1007/s10764-021-00206-6}

The original version of this article unfortunately contained mistakes in the citation in text and References. Author Julia Boughner's surname was inadvertently spelled as "Broughner".

The original article has been corrected.

The original article can be found online at https://doi.org/10.1007/s10764-021-00206-6

\section{Mark F. Skinner}

mskinner@sfu.ca

1 Department of Archaeology, Simon Fraser University, Burnaby, B.C, Canada 